\title{
Effects of the width and lay-up of sugi cross-laminated timber (CLT) on its dynamic and static elastic moduli, and tensile strength
}

\author{
Hirofumi Ido $^{1}$ Hirofumi Nagao ${ }^{1} \cdot$ Masaki Harada $^{1} \cdot$ Hideo Kato $^{1} \cdot$ \\ Junko Ogiso $^{1} \cdot$ Atsushi Miyatake $^{1}$
}

Received: 26 May 2015/Accepted: 27 October 2015/Published online: 29 December 2015

(C) The Japan Wood Research Society 2015

\begin{abstract}
Cross-laminated timber (CLT) has recently emerged as a new wood product that utilizes a large quantity of domestic lumber. This study aims to analyze the effects of width and lay-ups on the tensile strength of CLT. To this end, the elastic modulus of sugi CLT with different lay-ups was measured by dynamic and static methods. Moreover, tensile tests were conducted for different widths and lay-ups of CLT. Results indicate that the apparent bending Young's modulus, as calculated using the dynamic method, is directly proportional to the measured Young's modulus in static method for each lay-up. Furthermore, there was no significant effect of width on the tensile strength in the range of 150, 300, and $600 \mathrm{~mm}$. However, the variations in lay-ups affected the tensile strength as follows: CLT with larger ratio of the major strength direction lamina along the cross-section and with higher grade of lamina in the major strength direction showed higher tensile strength. The estimated tensile strength of CLT, as calculated using the Young's modulus of the lamina of each layer, and the tensile strength of lamina as simple substance was found to be in good agreement with the measured tensile strength of CLT.
\end{abstract}

Keywords Sugi $\cdot$ Cross-laminated timber $\cdot$ Elastic modulus $\cdot$ Tensile strength

Part of this study was presented in March 2015 at the Annual Meeting of the Japan Wood Research Society held in Tokyo.

Hirofumi Ido

ido@ffpri.affrc.go.jp

1 Forestry and Forest Products Research Institute, 1 Matsunosato, Tsukuba, Ibaraki 305-8687, Japan

\section{Introduction}

Cross-laminated timber (CLT) is an engineered wood product that was originally developed in Europe [1]. Lately, CLT has been increasingly used in buildings in Europe, the US, and Canada. Moreover, in countries like Japan, CLT has emerged as a new wood product that utilizes a large quantity of domestic lumber. Following this, the Japanese Agricultural Standard was immediately developed for CLT (JAS for CLT) [2] to respond to the expectations of developing CLT products. At present, there are no specifications in place to define the design strength of CLT, owing to the wide varieties of CLT that could be produced using domestic lumber. To this end, studies on CLT have just begun.

Tensile strength is one of the important characteristic values that determine the suitability of CLT in specific applications. CLT, when used as a wall panel, is subjected to tensile stress at the time of earthquake. With respect to CLT subjected to vertical loads, design procedures for compression members of CLT are described in the CLT handbook [3], and the compressive strength of CLT has been predicted using lamina property-based models by $\mathrm{Oh}$ et al. [4]. A compression strength perpendicular to the grain of CLT has been evaluated by Serrano et al. [5], Bogensperger et al. [6], and Ido et al. [7] in various CLT lay-up and loading conditions. With respect to the tensile strength of CLT, the US edition of the CLT handbook states that the grain parallel to the load should be included as the effective area for tension members [3]. However, to the best of our knowledge, the literature contains no experimental studies on the tensile strength of CLT apart from the tensile performance of connections for CLT $[8,9]$.

In this study, CLTs composed of sugi (Cryptomeria japonica) lamina in all layers were used as test specimens. 
Tensile tests were conducted for different widths and different lay-ups of CLT. Based on the results, the effect of width and lay-up on the tensile strength of CLT was evaluated. Furthermore, the average tensile strength of CLT was estimated as a function of the Young's modulus of each laminar layer. In addition, the elastic modulus of CLT with different lay-ups was measured using dynamic and static bending methods. The apparent bending Young's modulus under static bending was predicted from the dynamic bending to save the time and effort of static tests.

\section{Materials and methods}

\section{Types of CLT}

A summary of CLT and the representative values of the lay-up and size of CLT used in this study are shown in Table 1 and Fig. 1, respectively. In this study, we analyzed two main types of CLT, based on the width and lay-up. In each lay-up of CLT, three original CLT panels, whose width and length were approximately 2600 and $6000 \mathrm{~mm}$ in the CLT of different width specimen and approximately 2000 and $6000 \mathrm{~mm}$ in the CLT of different lay-ups specimen, respectively, were produced in Meiken Lamwood Corporation. Two test specimens were cut out by an original CLT panel, forming six test specimens in each type of testing.

CLTs of different widths were composed of 5-layer-5ply lay-up. The outer layers of the laminae run parallel to the major length direction of CLT, whereas the width of CLT is varied as 150,300 , and $600 \mathrm{~mm}$; these specimens are abbreviated as 5-5-Ma-150, 5-5-Ma-300, and 5-5-Ma600, respectively. Similarly, CLTs of different lay-ups were composed of 3-layer-3-ply, 3-layer-4-ply, and 5-layer-5-ply lay-ups. Here, the outer layers of CLT run parallel or orthogonal to the length of CLT (for example, as shown in Fig. 1, 3-layer-4-ply in the major strength direction and 3-layer-4-ply in the minor strength direction, abbreviated as 3-4-Ma and 3-4-Mi, respectively). CLTs of different lay-ups were all $300 \mathrm{~mm}$ width, in accordance with the bending test method of JAS for CLT [2].

Table 1 Summary of CLT used in this study

\begin{tabular}{lllll}
\hline Type of testing & $\begin{array}{l}\text { Abbreviated } \\
\text { name }\end{array}$ & Lay-up & $\begin{array}{l}\text { Direction of } \\
\text { outer layers }\end{array}$ & $\begin{array}{l}\text { Size (mm) depth } \times \\
\text { width } \times \text { length }\end{array}$ \\
\hline Different widths & $\begin{array}{l}\text { 5-5-Ma-150 } \\
\text { 5-5-Ma-300 }\end{array}$ & 5-layer-5-ply & Major & $150 \times 150 \times 6000$ \\
specimens
\end{tabular}

"Major" corresponds to the general direction of the grain, wherein the outer layer is parallel to the length of the CLT. On the other hand, "Minor" indicates the general direction of the grain, wherein the outer layer is perpendicular to the length of the CLT. For example, 3-layer-4-ply in the major direction and 3-layer-4-ply in the minor direction, abbreviated as 3-4-Ma and 3-4-Mi, respectively

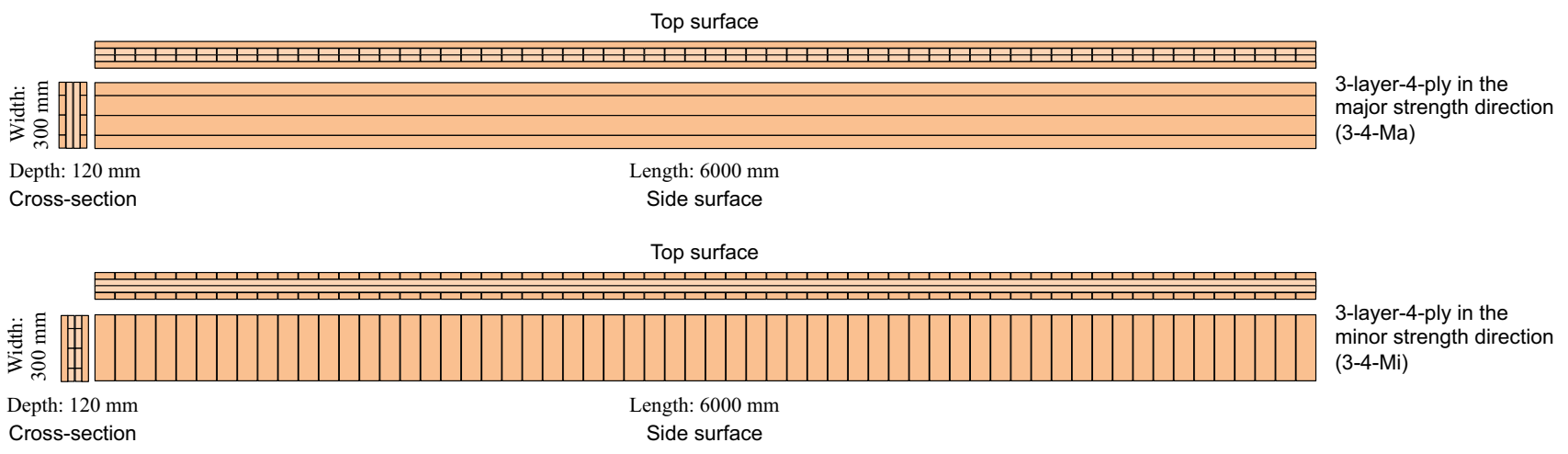

Fig. 1 Representative lay-up and size of CLT used in this study. Abbreviations for the type of CLT, refer to Table 1 
Table 2 Average and lower limit of bending Young's modulus of elasticity of laminae

\begin{tabular}{lllll}
\hline Layers in CLT & \multicolumn{2}{l}{ Lamina grade } & & \multicolumn{2}{l}{ Bending Young's modulus $\left(\mathrm{kN} / \mathrm{mm}^{2}\right)$} \\
\cline { 5 - 5 } & & & Average & Lower limit \\
\hline Outer-layer & M60A & Measured value & $7.09(12.6)$ & 5.4 \\
& & JAS Ref. [2] & 6.0 & 5.0 \\
Inner-layer & M30A & Measured value & $5.58(8.9)$ & 4.6 \\
& & JAS Ref. [2] & 3.0 & 2.5 \\
\hline
\end{tabular}

Value in bracket shows the coefficient of variation, in \%. JAS reference indicates the reference value provided by the Japanese Agricultural Standard for Cross-laminated timber [2]. Measured value of lower limit was based on $5 \%$ parametric tolerance limit for normal distribution with $75 \%$ confidence
All types of CLT with different widths and lay-ups were Mx60 and composed of M60A and M30A sugi laminae, as defined in JAS for CLT [2], in the outer and inner layers, respectively. The average and lower limit of bending Young's modulus of laminae [10], the results of which were obtained from the same lot used in this study, are shown in Table 2, together with the corresponding reference values defined in JAS [2]. All laminae analyzed in this study are of thickness $30 \mathrm{~mm}$ and width $105 \mathrm{~mm}$. In the typical process, laminae were finger-joint to a length of $15.0 \mathrm{~mm}$ along the vertical direction using aqueous polymer-isocyanate (API) adhesive. The laminae were pressed by applying a pressure of $0.6 \mathrm{MPa}$ for 3-layer-3-ply and 3-layer-4-ply CLT and $0.8 \mathrm{MPa}$ for other types of CLT using API adhesive, for a pressing time of $40 \mathrm{~min}$ regardless of the CLT thickness. There was no joint at the sides (narrow faces) of the laminae [11].

\section{Non-destructive tests}

The Young's modulus of CLT with different widths was measured using a longitudinal vibration method. Similarly, the elastic modulus of CLT corresponding to different layups was measured using dynamic and static methods. The Young's modulus by the longitudinal vibration method and the true bending Young's modulus without shear effect, and the shear modulus by the Timoshenko-Goens-Hearmon (TGH) flexural vibration method $[12,13]$ were measured as the dynamic method. In a typical process, true bending Young's and shear moduli by the TGH method were measured under in-plane and out-of-plane directions. During the process, CLT was supported at 0.224 times of its length from both the ends. Flexural vibration was excited at the center using a hammer. The motion of CLT was detected using a microphone or an acceleration pickup at the edge. In general, the first, third, and fifth resonance frequencies were obtained through a fast Fourier transform (FFT) comparator (Ono Sokki Co., Ltd., CF-4500). However, the true bending Young's and shear moduli were not measured in 3-3-Ma, 3-3-Mi and 3-4-Mi CLT along the out-of-plane direction because the resonance frequencies could not be detected.

Furthermore, the apparent bending Young's modulus was measured using the static bending test. In the typical process, the static bending test was conducted in third point loading with a span length of 21 times of depth, according to JAS for CLT [2], along both in-plane and out-of-plane directions. The load was applied within the elastic range. The apparent bending Young's modulus was calculated by measuring the displacement at the center of the CLT using a gauge. However, the apparent bending Young's moduli of 3-3-Mi CLT could not be determined along the out-ofplane, since the CLT sagged under its own weight when put on the support.

\section{Calculation of the apparent bending Young's modulus by the dynamic and static methods}

If the bending test is not conducted under a standard condition, then the bending Young's modulus can be converted to the standard condition using the following equation [14]:

$E=E_{b} \frac{\left\{1+2.4 h_{0}^{2}\left(\frac{E}{G}\right) /\left(3 L_{0}^{2}-4 a_{0}^{2}\right)\right\}}{\left\{1+2.4 h^{2}\left(\frac{E}{G}\right) /\left(3 L^{2}-4 a^{2}\right)\right\}}$

where $E$ is the bending Young's modulus under the testing condition, $E_{\mathrm{b}}$ is the bending Young's modulus under the standard condition, $(E / G)$ is the ratio of true bending Young's modulus to shear modulus; $h, L$ and $a$ are the depth, span, and distance between the reaction and the nearest load point under the testing condition, respectively; $h_{0}, L_{0}$ and $a_{0}$ are the depth, span, and distance between the reaction and nearest load point under the standard condition, respectively. The true bending Young's modulus, which was obtained from the TGH method, was converted to the apparent bending Young's modulus using the following equation that is obtained by transforming the Eq. (1)

$M O E_{\text {app }, \text { dynamic }}=E_{\mathrm{TGH}} \frac{1}{\left\{1+\frac{216}{230}\left(\frac{E_{\mathrm{TGH}}}{G_{\mathrm{TGH}}}\right)\left(\frac{h}{L}\right)^{2}\right\}}$ 
where $M O E_{\text {app,dynamic }}$ is the apparent bending Young's modulus in dynamic, $E_{\mathrm{TGH}}$ is the true bending Young's modulus determined by TGH method, and $G_{\mathrm{TGH}}$ is the shear modulus determined by TGH method. Using Eq. (2), the true bending Young's modulus obtained from the dynamic method was converted to the apparent bending Young's modulus. The loading condition, $h / L$, was $1 / 21$, consistent with the span length of 21 times the depth loading condition used in this study. The ratio of true bending Young's modulus to shear modulus, $\left(E_{\mathrm{TGH}} / G_{\mathrm{TGH}}\right)$, was determined by substituting the individual values obtained from the TGH method.

\section{Tensile test method}

Tensile tests were conducted on all types of CLT analyzed in this study using a tensile testing machine with $2000 \mathrm{kN}$

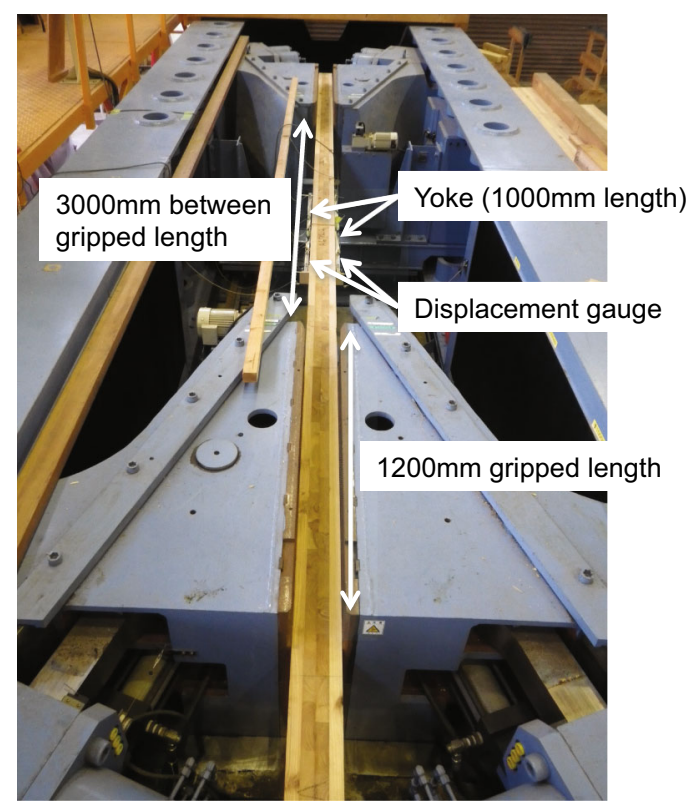

Fig. 2 The configuration used for the tensile tests capacity (Maekawa Testing Machine Mfg Co., Ltd., HZS200-LB4). The configuration of the tensile test is shown in Fig. 2. CLT lengths between grips were $3000 \mathrm{~mm}$ and the gripped lengths were $1200 \mathrm{~mm}$. The elongation of a CLT was measured using two displacement gauges attached to both sides of the CLT. Each gauge was connected to a yoke, which was supported by two nails for connection to the CLT, at a distance of $1000 \mathrm{~mm}$. The gauge head was then placed in contact with a wooden-angled target attached by one of the nails and a screw. Therefore, when a CLT was extended, the displacement gauges could measure elongation between the two nails (over a length of $1000 \mathrm{~mm}$ ). The maximum load was divided by the crosssectional area, which in turn was used to calculate the tensile strength. After failure, specimen of length about $30 \mathrm{~mm}$ was cut from a region closer to the failure position and the moisture content was measured using the oven-dry method.

\section{Estimation of the tensile strength of CLT}

The average tensile strength of CLT was estimated using the "transformed section" [15] and the formula [16] for calculating the specified design strength of glued laminated timber [17]. As the data of lamina used for this estimation, the measured average Young's modulus by the longitudinal vibration method and measured average tensile strength, 7.14 and $25.0 \mathrm{~N} / \mathrm{mm}^{2}$ in M60A and 5.93 and $19.2 \mathrm{~N} / \mathrm{mm}^{2}$ in M30A, respectively, were used. These laminae were obtained from the same lot of lamina tested in these CLTs [10]. As shown in Fig. 3, estimation procedure can be explained using the 5-5-Ma CLT. In the actual cross-sectional area, Young's modulus was allocated for each layer. In this study, the average Young's modulus-specifically, $7.14 \mathrm{kN} / \mathrm{mm}^{2}$ for M60A and $5.93 \mathrm{kN} / \mathrm{mm}^{2}$ for M30A, as measured by the longitudinal vibration method-was allocated to the outer and inner layers, respectively. In contrast, the Young's modulus in the minor strength direction, which corresponds to the Young's modulus
Fig. 3 The procedure adopted for the estimation of CLT tensile strength using

"transformed section"
Actual cross-sectional area

Young's modulus $\left(\mathrm{kN} / \mathrm{mm}^{2}\right)$

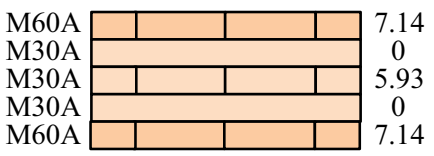

Young's modulus in the minor strength direction is assumed to be zero in the cross-section
Transformed cross-sectional area

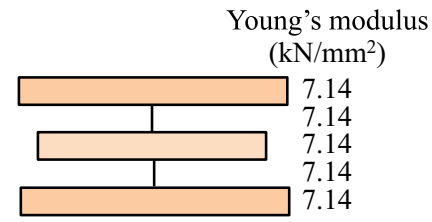

The width of the cross-section is transformed according to the ratio of the largest Young's modulus

Transformed cross-sectional area / Actual cross-sectional area $=0.566$ 
perpendicular to the grain, was assumed to be zero along the cross-section, because of the absence of joints at the sides. In the transformed cross-sectional area, the width of cross-section was transformed according to the ratio of the largest Young's modulus. The estimated tensile strength was then calculated using the following equation [16]:

$\sigma_{\text {t-est }}=\sigma_{\text {lamina }} \times\left(A_{\text {transformed }} / A_{\text {actual }}\right)$

where $\sigma_{\text {t-est }}$ is the estimated tensile strength of CLT, $\sigma_{\text {lamina }}$ is the tensile strength of the lamina with the largest Young's modulus, $A_{\text {transformed }}$ is the transformed crosssectional area, $A_{\text {actual }}$ is the actual cross-sectional area. In this study, the average tensile strength (i.e., $25.0 \mathrm{~N} / \mathrm{mm}^{2}$ for M60A and $19.2 \mathrm{~N} / \mathrm{mm}^{2}$ for M30A) was used for $\sigma_{\text {lamina }}$.

Table 3 Average of non-destructive tests for difference widths of the CLT

\begin{tabular}{lll}
\hline Type of CLT & $\rho\left(\mathrm{kg} / \mathrm{m}^{3}\right)$ & $E_{\mathrm{fr}}\left(\mathrm{kN} / \mathrm{mm}^{2}\right)$ \\
\hline $5-5-\mathrm{Ma}-150$ & 415 & 4.59 \\
& $(1.15)$ & $(2.97)$ \\
$5-5-\mathrm{Ma}-300$ & 409 & 4.74 \\
& $(1.36)$ & $(3.59)$ \\
$5-5-\mathrm{Ma}-600$ & 411 & 4.71 \\
& $(1.78)$ & $(2.58)$ \\
\hline
\end{tabular}

Value in bracket shows the coefficient of variation, in \%. Abbreviations for the type of CLT, refer to Table 1

$\rho$ density at the test, $E_{\mathrm{fr}}$ Young's modulus determined using longitudinal vibration method

\section{Results and discussion}

\section{Comparison of the apparent bending Young's modulus, as calculated using the dynamic and static methods}

Tables 3 and 4 summarize the results of non-destructive tests, and Fig. 4 shows the comparison of apparent bending Young's modulus calculated using the static and dynamic methods. Except for that along the out-of-plane minor strength direction, the apparent bending Young's modulus estimated using the dynamic method is slightly greater than that determined using the static method. More specifically, the apparent bending Young's modulus, as determined from both the methods, was straight-lined in every plane and strength direction. This implies that the apparent bending Young's modulus can be measured by either of the methods. However, it is more economical, in terms of time and effort, to measure the apparent bending Young's modulus in the dynamic method, when several types of CLT are to be tested. In addition, in this study, $300 \mathrm{~mm}$ width CLT was used, in accordance with JAS for CLT [2], although it remains unclear whether similar results could be achieved with different CLT widths. No significant correlation was observed between the Young's modulus calculated using the dynamic method and the shear modulus determined by the TGH method.

Table 4 Average of non-destructive tests for difference lay-ups of the CLT

\begin{tabular}{|c|c|c|c|c|c|c|c|c|}
\hline \multirow[t]{2}{*}{ Type of CLT } & \multirow[t]{2}{*}{$\rho\left(\mathrm{kg} / \mathrm{m}^{3}\right)$} & \multirow[t]{2}{*}{$E_{\mathrm{fr}}\left(\mathrm{kN} / \mathrm{mm}^{2}\right)$} & \multicolumn{3}{|c|}{ Out-of-plane } & \multicolumn{3}{|l|}{ In-plane } \\
\hline & & & $\begin{array}{l}E_{\mathrm{TGH}} \\
\left(\mathrm{kN} / \mathrm{mm}^{2}\right)\end{array}$ & $\begin{array}{l}G_{\mathrm{TGH}} \\
\left(\mathrm{kN} / \mathrm{mm}^{2}\right)\end{array}$ & $\begin{array}{l}M O E_{\text {app,static }} \\
\left(\mathrm{kN} / \mathrm{mm}^{2}\right)\end{array}$ & $\begin{array}{l}E_{\mathrm{TGH}} \\
\left(\mathrm{kN} / \mathrm{mm}^{2}\right)\end{array}$ & $\begin{array}{l}G_{\mathrm{TGH}} \\
\left(\mathrm{kN} / \mathrm{mm}^{2}\right)\end{array}$ & $\begin{array}{l}M O E_{\text {app,static }} \\
\left(\mathrm{kN} / \mathrm{mm}^{2}\right)\end{array}$ \\
\hline \multirow[t]{2}{*}{ 3-3-Ma } & 413 & 5.71 & - & - & 7.00 & 5.79 & 0.840 & 5.24 \\
\hline & $(1.57)$ & $(3.26)$ & & & $(4.93)$ & (4.39) & $(6.95)$ & $(4.30)$ \\
\hline \multirow[t]{2}{*}{ 3-3-Mi } & 411 & 2.41 & - & - & - & 2.49 & 0.813 & 2.16 \\
\hline & $(1.35)$ & (4.07) & & & & (3.84) & $(24.8)$ & $(3.48)$ \\
\hline \multirow[t]{2}{*}{ 3-4-Ма } & 405 & 4.43 & 7.83 & 0.163 & 6.65 & 4.50 & 0.754 & 4.10 \\
\hline & (1.11) & (3.47) & (2.69) & (4.10) & $(3.47)$ & (3.67) & $(6.32)$ & (3.23) \\
\hline \multirow[t]{2}{*}{ 3-4-Mi } & 413 & 3.30 & - & - & 1.12 & 3.45 & 0.726 & 3.10 \\
\hline & $(0.525)$ & $(4.10)$ & & & (11.5) & (4.98) & (14.4) & $(5.68)$ \\
\hline \multirow[t]{2}{*}{ 5-5-Ма } & 412 & 4.71 & 6.85 & 0.242 & 5.90 & 4.75 & 0.820 & 4.31 \\
\hline & (1.16) & (4.72) & $(7.63)$ & (13.9) & (6.10) & (3.33) & (3.99) & $(3.72)$ \\
\hline \multirow[t]{2}{*}{ 5-5-Mi } & 403 & 2.62 & 1.31 & 0.256 & 1.52 & 2.72 & 0.740 & 2.36 \\
\hline & $(1.27)$ & (4.92) & (3.63) & (41.2) & (4.44) & (5.97) & (12.3) & (6.20) \\
\hline
\end{tabular}

Value in bracket shows the coefficient of variation, in \%. Abbreviations for the type of CLT, refer to Table 1

$\rho$ density at the test, $E_{\mathrm{fr}}$ Young's modulus determined by using the longitudinal vibration method, $E_{\mathrm{TGH}}$ true bending Young's modulus determined by TGH method, $G_{\mathrm{TGH}}$ shear modulus determined by TGH method, $M O E_{\text {app,static }}$ apparent bending Young's modulus determined by static bending test 

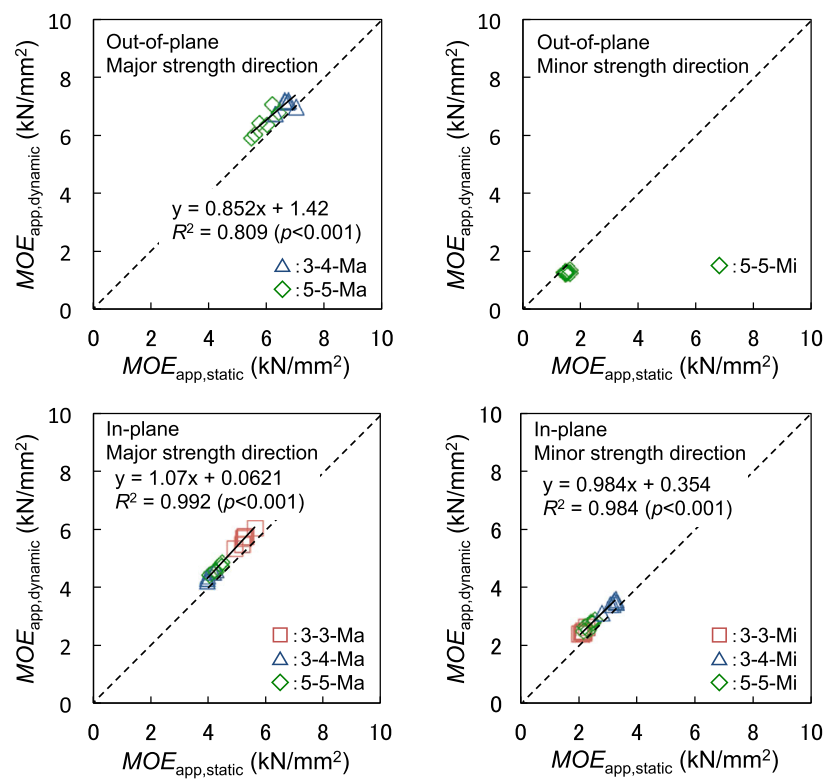

Fig. 4 Relationship between the apparent bending Young's modulus determined using the static method, $M O E_{\text {app,static, and which is }}$ calculated using the dynamic method, $M O E_{\text {app,dynamic. Abbreviations }}$ for the type of CLT, refer to Table 1

Table 5 Average of tensile tests for different widths of the CLT

\begin{tabular}{llll}
\hline Type of CLT & $M C(\%)$ & $E \mathrm{t}\left(\mathrm{kN} / \mathrm{mm}^{2}\right)$ & $\sigma_{\mathrm{t}}\left(\mathrm{N} / \mathrm{mm}^{2}\right)$ \\
\hline $5-5-M a-150$ & 10.9 & 3.97 & 13.1 \\
& $(4.56)$ & $(3.53)$ & $(8.28)$ \\
$5-5-M a-300$ & 11.0 & 4.32 & 12.7 \\
& $(3.08)$ & $(7.88)$ & $(7.81)$ \\
$5-5-$ Ma-600 & 11.0 & 4.35 & 12.6 \\
& $(1.48)$ & $(2.28)$ & $(6.00)$ \\
\hline
\end{tabular}

Value in bracket shows the coefficient of variation, in \%. Abbreviations for the type of CLT, refer to Table 1

$M C$ moisture content determined using oven-dry method, $E_{\mathrm{t}}$ tensile elastic modulus, $\sigma_{\mathrm{t}}$ tensile strength

\section{Failure mode of CLT}

Tables 5 and 6 summarize the results of the tensile tests. In all cases, with different width and lay-up specimens, the relationship between load and deformation was mostly linear until the failure. A typical failure occurred at the finger-joint or knot in the top surface lamina when the specimen was the major strength direction CLT. In contrast, in the inner part of the major strength direction lamina, failure occurred near the boundary (adjacent sides of lamina) of the adjoining minor strength direction lamina, not at the finger-joint or knot. The majority of the minor strength direction lamina did not fail but simply separated because no joint was present at the sides of the lamina.
Table 6 Average of tensile tests for different lay-ups of the CLT

\begin{tabular}{llll}
\hline Type of CLT & $M C(\%)$ & $E \mathrm{t}\left(\mathrm{kN} / \mathrm{mm}^{2}\right)$ & $\sigma_{\mathrm{t}}\left(\mathrm{N} / \mathrm{mm}^{2}\right)$ \\
\hline 3-3-Ma & 11.8 & 5.19 & 16.8 \\
& $(3.54)$ & $(4.03)$ & $(8.20)$ \\
3-3-Mi & 12.0 & 2.12 & 6.66 \\
& $(4.75)$ & $(7.64)$ & $(14.4)$ \\
3-4-Ma & 11.9 & 4.04 & 12.0 \\
& $(3.96)$ & $(3.37)$ & $(9.62)$ \\
3-4-Mi & 11.9 & 3.03 & 10.1 \\
& $(7.80)$ & $(7.89)$ & $(9.94)$ \\
5-5-Ma & 11.0 & 4.34 & 14.3 \\
& $(5.54)$ & $(3.83)$ & $(7.79)$ \\
5-5-Mi & 11.7 & 2.24 & 8.33 \\
& $(3.04)$ & $(4.45)$ & $(4.73)$
\end{tabular}

Value in bracket shows the coefficient of variation, in \%. Abbreviations for the type of CLT, refer to Table 1

$M C$ moisture content determined by using the oven-dry method, $E_{\mathrm{t}}$ tensile elastic modulus, $\sigma_{\mathrm{t}}$ tensile strength

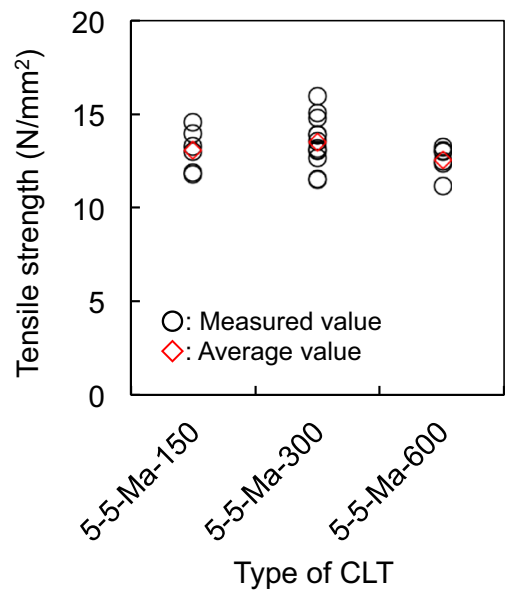

Fig. 5 Relationship between the width of CLT and tensile strength. The plotted results for 5-5-Ma-300 CLT include results for 5-5-Ma CLT. Abbreviations for the type of CLT, refer to Table 1

\section{Effect of specimen width on tensile strength}

The relationship between width of CLT and tensile strength is shown in Fig. 5. The 5-5-Ma-300 CLT, which was considered to analyze the effect of specimen width, and 5-5-Ma CLT, which was considered to analyze the effect of lay-up, are of the same size and lay-up. They are plotted together in Fig. 5 and in the following figures. Tukey-Kramer HSD test was performed to determine the effect of width. Results indicate no significant differences in average of tensile strength at $5 \%$ significance level. Therefore, the effect of specimen width can be considered negligible as long as for the width range of 150,300 , and $600 \mathrm{~mm}$. 


\section{Effect of lay-up on tensile strength}

Figure 6 shows the relationship between lay-up and tensile strength. The horizontal axis of CLT types was classified in order from higher to lower average of tensile strength. It was found that this order corresponds to the ratio of the major strength direction along the cross section of CLT. The reason underlying this observation could be explained based on the fact that the laminae in the major strength direction bear the tensile stress, while the laminae in minor strength direction do not bear the tensile strength owing to the absence of joint at the sides. In the case of 3-4-Ma and 3-4-Mi CLT, wherein the ratio of the major and minor strength direction along the cross section is the same, the average of tensile strength was higher in 3-4-Ma CLT than that in 3-4-Mi CLT. This result implies that the M60A laminae of outer layers in 3-4-Ma CLT bear the tensile stress, while M60A laminae of outer layers in 3-4-Mi do not bear the tensile strength.

\section{Comparison between the estimated and measured value of tensile strength}

The estimated average tensile strength of CLT was compared with the measured tensile strength of CLT shown in Fig. 7. As is seen, the estimated average tensile strength well coincides with the measured tensile strength for all lay-ups, along both the major and minor strength directions. This implies that the tensile strength of CLT could be estimated with high accuracy, if the Young's modulus and tensile strength of lamina with the same lot used in CLT are measured in advance at the manufacturing facility.

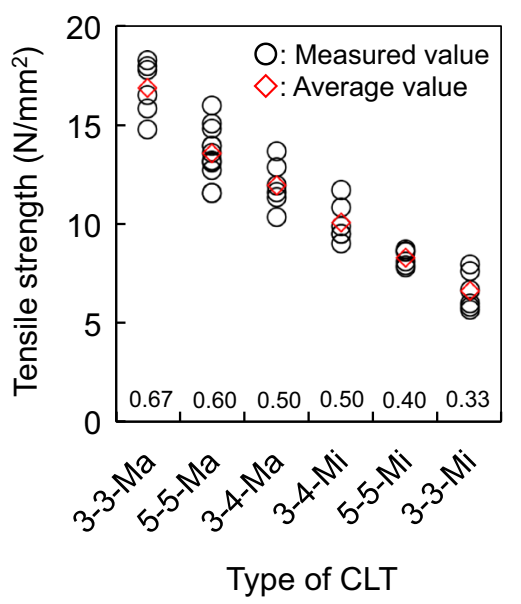

Fig. 6 Relationship between the lay-up of CLT and tensile strength. The Plotted results for 5-5-Ma CLT include results for 5-5-Ma-300 CLT. The numerical values in the graph are ratios of the major strength direction in the cross-section. Abbreviations for the type of CLT, refer to Table 1

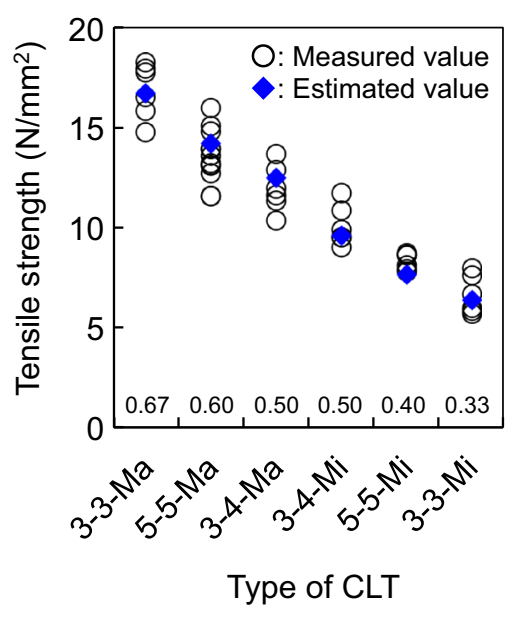

Fig. 7 Comparison between the estimated and measured tensile strengths of CLT. The plotted results for 5-5-Ma CLT include the results for 5-5-Ma-300 CLT. The numerical values in the graph are ratios of the major strength direction in the cross-section. Abbreviations for the type of CLT, refer to Table 1

\section{Conclusions}

Elastic modulus of CLT with different lay-ups was measured using dynamic and static methods. The apparent bending Young's modulus, which was calculated by the dynamic method, was in good agreement with the values of Young's modulus determined using the static method for each lay-up. Furthermore, tensile tests were conducted with different widths and lay-ups of CLT to evaluate the effects of these factors on the tensile strength of CLT. Results indicate no significant effects of width on the tensile strength for widths as long as in the range of 150,300 , and $600 \mathrm{~mm}$. However, variations in lay-ups affected the tensile strength as follows: CLT with larger ratio of the major strength direction lamina along the cross-section and higher grade of lamina in the major strength direction showed higher tensile strength. Furthermore, the estimated average tensile strength of CLT, as calculated using Young's modulus of the lamina of each layer, and the tensile strength were found to be in good agreement with the measured tensile strength of CLT. These results contribute to saving time and effort in the evaluation of elastic modulus and tensile strength when many types of CLT are to be tested. In this study, M60A and M30A laminae were used as the outer and the inner layers, respectively, and the laminae were not side-joint. However, it is not clear as to whether these results are applicable to similar systems; for example, M90A lamina used as outer layers, or side-joint laminae used in the CLT. Further studies are required to validate the suitability of the results to other systems.

Acknowledgments This study was conducted under a subsidiary project of the Forestry Agency in supplementary budget for fiscal 2013, the project for promotion of utilization of CLT and other new products and new technology. 


\section{References}

1. FPInnovations (2011) Introduction to cross-laminated timber. CLT Handbook: cross-laminated timber Canadian edition, FPInnovations, Quebec, Chapter 1, p 1

2. Notification No. 3079 of the Ministry of Agriculture, Forestry and Fisheries, December 20 (2013) Japanese Agricultural Standard for Cross-Laminated Timber (in Japanese), Ministry of Agriculture, Forestry and Fisheries, Tokyo, Japan

3. Ross LA, Gagnon S, Keith E (2013) Structural design of crosslaminated timber elements. CLT Handbook: cross-laminated timber US edition, FPInnovations, Pointe-Claire, Chapter 3, pp 5-6

4. Oh JK, Lee JJ, Hong JP (2015) Prediction of compressive strength of cross-laminated timber panel. J Wood Sci 61:28-34

5. Serrano E, Enquist B (2010) Compression strength perpendicular to grain in cross-laminated timber (CLT). In: Proceedings of World Conference on Timber Engineering, Riva del Garda, Italy, I, pp 153-154

6. Bogensperger T, Augustin M, Schickhofer G (2012) Properties of CLT-panels exposed to compression perpendicular to their plane. In: Proceedings of CIB-W18. Växjö, Sweden, Paper 44-12-1

7. Ido H, Nagao H, Miura S, Miyatake A (2014) Compression strength properties perpendicular to the grain of cross-laminated timber (CLT) composed of sugi laminations (in Japanese). Mokuzai Gakkaishi 60:16-22

8. Nakashima S, Kitamori A, Mori T, Komatsu K (2012) Evaluation of tensile performance of drift pin joint of cross laminated timber with steel inserted plate. In: Proceedings of World Conference on Timber Engineering, Auckland, New Zealand, Volume 1, pp 417-424

9. Stecher G, Kögl J, Beikircher W (2014) Mechanical behavior of dovetail connections for cross laminated timber wall elements. In: Proceedings of World Conference on Timber Engineering, Quebec, Canada

10. Ogiso J, Nagao H, Harada M, Kato H, Ido H, Miyatake A (2015) Strength evaluations of sugi CLT by laminae strength data. Part 1
Strength of bending, compression parallel to the grain and tension parallel to the grain of sugi laminae (in Japanese). In: Abstracts of the 65th annual meeting of the Japan Wood Research Society (Poster), 3/16-3/18, 2015, Tokyo, Japan, D17-P-S13

11. Forestry and Forest Products Research Institute, Hokkaido Research Organization, Japan Cross Laminated Timber Association (2015) Promotion in practical use of CLT (Collection and analysis of strength data) in the project for promotion of utilization of CLT and other new products and new technology (in Japanese). Forestry and Forest Products Research Institute, Hokkaido Research Organization, Japan Cross Laminated Timber Association, Tsukuba, Sapporo, Tokyo, p 2

12. Kubojima Y, Yoshihara H, Ohta M, Okano T (1996) Examination of the method of measuring the shear modulus of wood based on the Timoshenko theory of bending. Mokuzai Gakkaishi 42:1170-1176

13. Kubojima Y, Tonosaki M (2012) Young's and shear moduli of glued laminated timber composed of different species obtained by a flexural vibration test. Holzforschung 66:871-875

14. Architectural Institute of Japan (2006) Standard for structural design of timber structures (in Japanese). Architectural Institute of Japan, Tokyo, pp 163-164

15. Timoshenko S (1958) Strength of materials. Part I Elementary theory and problems. Third Edition. Van Nostrand Reinhold Company, New York, pp 217-221

16. Miyatake A, Nagao H, Kamiya F, Hiramatsu Y, Kawai N, Nakajima S, Tsuchimoto $\mathrm{T}$ (2008) Evaluation of existing formulae for calculation of bending, compression and tensile strength of Glulam (in Japanese). In: Summaries of technical papers of annual meeting architectural institute of Japan, Hiroshima, Japan, Structures III, pp 273-274

17. Notification No. 1024 of the Ministry of Land, Infrastructure, Transport and Tourism, June 12 (2001) Establishment of special allowable unit stress and special material strength (in Japanese), Ministry of Land, Infrastructure, Transport and Tourism, Tokyo, Japan 